\title{
Developing Early Childhood Ability in Understanding Rules Using Combination of Role-Playing Model and Question- Answer Method Through Medium of Traffic Signs
}

\author{
Novitawati $^{1 *}$, Juma Abdu Wamaungu ${ }^{2}$, Silvy Widya Astuti ${ }^{1}$, \\ 'Department of Early Childhood Education, Universitas Lambung Mangkurat, Banjarmasin, Indonesia. \\ ${ }^{2}$ Faculty of Education, Kyambogo University, Uganda.
}

\begin{tabular}{|c|c|}
\hline ARTICLE INFO & A B S TRACT \\
\hline \multirow[t]{2}{*}{$\begin{array}{l}\text { Received: 09-03-2017 } \\
\text { Revised: 08-05-2017 } \\
\text { Accepted: 07-06-2017 } \\
\text { Keywords: } \\
\text { Ability, development, role- } \\
\text { playing, question-answer. }\end{array}$} & $\begin{array}{l}\text { This research was performed by teachers in the classroom in order to develop } \\
\text { children's ability in understanding rules. The subject of the research was group B } \\
\text { students at Insan Kamil Kindergarten of Banjarmasin in the } 2^{\text {nd }} \text { semester academic } \\
\text { year of 2016/2017. This research used classroom action research with qualitative } \\
\text { approach and research is considered as successful if the achievement indicators based } \\
\text { on teacher activity, children activity, and result of development achievement are } \\
\text { accomplished. The results of the research in developing the children's ability to } \\
\text { understand the rules applied the combination of role-playing model and question- } \\
\text { answer method through medium of traffic signs. }\end{array}$ \\
\hline & $\begin{array}{l}\text { (c) } 2018 \text { The Authors. Journal of K6, Education, and Management (j-K6EM). ISSN: } 2580-2135 . \\
\text { Published by Graduated Program of Educational Management, Universitas Lambung } \\
\text { Mangkurat, Banjarmasin, Indonesia. This is an open access article under the open journal } \\
\text { systems } 3 \text {. }\end{array}$ \\
\hline
\end{tabular}

*Author correspondence: Novitawati; E-mail: novitawati@ulm.ac.id 


\section{Introduction}

Formal education in schools as well as informal education have important roles in children's social and moral development. The development process of student's social and moral values is always related to the learning process. It means that learning process determines the students' ability to act and behave socially in accordance with the norm of religion, tradition, law, and other norms apply in the society.

The social learning process must be instilled since early childhood because it is susceptible period to learn. Therefore, it is easy for them to receive variety of information in the environment. In order to make the development of children optimal, support is needed from conducive environment, so all the children potential (i.e. physical, language, intellectual/cognitive, emotional, social, moral, and religious) can be directed to the development of attitudes, knowledge, skills, and creativity to adapt to the environment as well as for future growth development (Latif et al., 20I4).

Early childhood education needs to be held to develop all potential of the children. Kindergarten is formal early childhood education level after Play Group. Early childhood is indicated by rapid psychosocial growth. Emotional and social development is the development process of children's ability to adapt to the wider social world. At this development stage, the children are expected to understand other, that is to describe characteristics, identify their thought, feeling, and desire, and able to view from other people's perspective without "losing" their own identity (Soetjinongsih, 2012).

Social development also very much ensures moral development because moral behavior generally is the fundamental elements in social behavior. A student will only be able to behave socially in particular social situations adequately if he/she knows how to behave according to the moral norms needed in such social situations. The important thing should be performed by a teacher as early as possible at the beginning of school is to instill and cultivate the fundamental of moral, social, norm, ethics, and religious education for every single child. All of these is necessary for the development of children personality and very useful for the children future lifelong and wellbeing.

Feeling shame when doing bad thing should be instilled in children since the early school. It is important because shame could filter good or bad deed for the children. Children's ability to distinguish good or bad deed is important and useful in their social lives in the community which sometimes could be hostile. If the child feels shame to do bad things, then he/she can be categorized as child with noble character.

Along with their social development, preschoolers are also experiencing moral development. Moral development is development related to the rules and conventions about what should be implemented by humans in their interaction. Babies are born with a sense of fairness (without moral compass) but they have innate sense of morality ready to develop. Therefore, through interacting with others (parents, relatives, and peers), the children learn to understand to select which one is good behavior that may be done, and which the bad one that should be avoided (Mar'at, 2010).

Understanding simple rules is important for Kindergartener such as introducing them about traffic signs by using simple media. Kindergartener need to be taught to recognize traffic signs. The learning is necessary to provide them knowledge and skills about safety. Learning about traffic signs is to prepare the children as the next generation to face various problems in obeying rules as well as building attitudes and behavior in accordance with the neighborhood community.

In fact, in development process of understanding the rules on group B children at Insan Kamil Kindergarten of North Banjarmasin District, there is problem in the learning activities, which is the children have not been able to understand the rules well yet. From I9 children, it was about I children who are still not developing optimally. There was 5 children obtained I star, 6 children obtained 2 stars, 6 children obtained 3 stars, and 2 children obtained 4 stars.

This occurs due to lack of activity or material in Kindergarten which should have introduced the children about various types of rules. The 
learning activities were mostly performed by sitting on the desk and doing the tasks on children workbooks. The teachers were rarely utilizing variety of models and methods in teaching to introduce the children about daily life rules that invite them to move actively during the learning. Consequently, children development in emotional social aspects is still deficient. The children still face difficulties in understanding daily life rules and the intention of the rules. This is because the children are predominantly listening and looking at pictures in the book. If this condition never ceases to be until they grow older, then they will behave unmannered/undesirable by the community members.

Attempts to develop student's social emotional aspect in understanding rules is by presenting the methods, models, and appropriate media in the learning activities. So, it is expected to overcome lack of the traffic rules understanding problem. for this reason, the researcher chose combination of role-playing model and question-answer method through applying traffic signs medium for them to practice understanding the rules.

Role playing Model is a learning model giving chance for the students to place themselves as the character and in situations that can increase their awareness of values and beliefs. This Model is very intriguing for the students. It allows the learning process to be dynamic and full of enthusiasm, impressive and last long in their memory (Shoimin, 20I4).

Question-Answer method is learning method performed by asking questions that leads the students to understand the subject matter in order to achieve the learning objectives. Question-Answer is a method that can enhance the students' achievement and excitement in the learning being delivered. Through this method, it will create active learning for students. So, the students can make the most of this moment to expand their knowledge, insight, and increase the mastery of learning material. In addition, the teacher can exercise this situation to provide maximum understanding to the students. Consequently, the students can receive the learning materials provided maximally. The method is using props and presented by applying playing model which is favored by the students, so they will love to learn because the traffic signs medium makes learning more fun.

Steps of the activity of combination using role playing model and question-answer method through applying traffic signs medium are as follows: (I) determining the topic. (2) formulating specific learning objectives and provide explanation of the competencies to be achieved. (3) teacher prepares/sets up stories to be presented. (4) teacher forms groups of students and distributes the role to the students. (5) students enact role playing activity in accordance with teacher directions. (6) teacher and students discuss the role-playing activities that have been performed. (7) phrasing questions appropriately in accordance with the specific learning objectives. (8) teacher provides problems to students. (9) teacher asks questions to the class. (I0) teacher provides enough time to think about the answer. (II) teacher provides the conclusion in general.

The reason of combining role playing model with question-answer method as well as applying traffic signs medium to develop student ability in understanding rules is because students learning activity in understanding the rules will become more active, creative, and fun since the students are directly involved in the activity implementation. The students are free to explore the activity as well as the applying of media that appeal to the students. Both are considered very suitable in instilling the concept of various rules for students. While playing the role-playing model, students can learn about various traffic signs through simple role-play activity. Questionanswer method is also important in the activity, for the implementation of question-answer can make the class becomes livelier. It is because the students are actively participated and trying to listen to the teacher's question well and trying to provide the right answer. Accordingly, the students are thinking actively, not only listening passively. So, student's knowledge through Role Playing activity is more extended by questionanswer activity.

In addition, discipline should be implemented to the students since early age, so that the children will behave in good manner. It will be very useful in supporting their future development of other aspects as well as for their lives. 
In learning Process, instilling independent attitude and understanding of the class rules requires learning methods and models to maximize the achievements or learning objectives that have been set. The use of the appropriate teaching method should be considered. Therefore, the teaching methods used to achieve the specific learning objectives should be able to attract the students' interest and attention. With the presentation of interesting medium, it will raise students' curiosity and interest. The high interest and attention intensity are pro-condition for the achievement of optimal learning objectives.

Combination of role-playing Model and Question-Answer Method which is performed in the learning through applying traffic signs medium at Insan Kamil Kindergarten is a mean/tool that can be used for the students to develop social emotional skills in understanding the rules. The use of role-playing model and Question-Answer method in the traffic signs introduction will make students easier to understand the rules in their daily lives, including traffic rules. The students will be engaged in learning when performing role-play activity, and the knowledge acquired by the students in roleplay activity will be more attached to their minds by the implementation of question-answer activity. This can help students to understand better and with attractive concept, it will enhance student interest in learning to the most.

\section{Methodology}

A good methodology should bring the researcher to achieve of the objective (Dalle, 2010; Dalle et al., 2017). Qualitative approach is used in this classroom action research, in which the focus is human and their interaction in social context. The research was conducted in natural context. Qualitative research also aims to understand the research subject in depth and interpretative. It means that it is searching for findings of meaning (Son, 2012).

This research is classroom action research. Classroom Action research is one of teachers or practitioner efforts in form of various activities performed to improve a state or condition which is not or less satisfying and/or to improve the learning quality in classroom. Classroom Action research is an activity related to teacher duties directly in the field. In short, Classroom Action Research is practical research conducted in classroom and aims to improve the learning practices (Kasbolah \& Sukarnyana, 2012)

The classroom action research (CAR) procedure is (I) Planning, (2) Implementation, second phase of the action research is design implementation. The thing to keep in mind is that in the second phase, teacher as the implementer must remember and obey the planning, but he/she must also be fair while performing learning process. (3) Observation, observations activity in CAR can be aligned with the data collection in formal research. (4) Reflection, activity to restating what is already conducted. Reflection is very appropriate to be performed when the teacher is already finished doing the action, then discussing with the researcher about the implementation of design action. The core of action research is when teacher observes what he was doing, and then reflects to himself/herself. In other words, the teacher reflects to himself/herself doing the "dialogue "to find satisfactory things because it was in accordance with the design and scrutinize the things that needs improvement carefully (Arikunto, 20I4).

Factors under study in the classroom action research consist of 3 , namely teacher, students, and results of student's emotional social development, especially in understanding rules.

Data analysis process was started by reviewing available data from a variety sources, from written observations, photo documentation, and assessment format.

The obtained data through observation and documentation was re-written, explained, and then sorted according to the research focus.

Data analysis technique was performed by viewing and assessing the activity phases, starting from the introduction, the main and the closing through the teacher activity assessment rubric.

The score provisions on observation sheet were: Score of I was given to teachers who performed poorly, Score of 2 was given to teachers who performed fairly, Score of 3 was given to teachers who performed well, and Score 4 is given to teachers who performed excellent. 
Students activity data and data analysis technique in the observing and assessing the activity phases were viewed and assessed from several aspects.

The score provisions on the observation sheet were Score of I was given to students who performed less active, Score of 2 was given to students who performed quite active, Score of 3 was given to students who performed actively, Score of 4 is given to students who performed very active. From Development Result Data, the Assessment in the kindergarten in general does not use numbers such as in secondary school but using stars. The way to record the results is by using symbols to indicate the achievement level of student's development (Ministry of Education, 2010).

For student who has not developed yet (BB) in accordance with the indicators and not able to perform the task or does not response, then the student is given I $\star$, student who is already begin to develop (MB) in accordance with the indicators and able to perform or give a response with the help of teacher, then the student is given $2 \star \star$, student who has developed according to expectations (BSH) in accordance with the indicators and able to perform the task or give a response with a little help of teacher, then the student is given $3 \star \star \star$, student who is already well developed (BSB) exceeds the indicator and able to perform the task or give a response without the help of teacher, then the student is given $4 \star \star \star \star$.

The Achievement Indicators in this research were (I) on the teacher activity, it was said to be successful if the teacher could perform the learning using Combination of role-playing model and question-answer method through applying traffic signs medium with score of $\geq 36$ for excellent category. (2) Student activity was said to be successful if the student activity in developing emotional social aspect of Understanding the Rules through Combination of role-playing model and question-answer method by applying traffic signs medium seen in classical obtained active or very active category at least (80\%). (3) Emotional social aspect (understand the rules) through combination of role-playing model and question-answer method by applying traffic signs medium was said to be successful if student can individually manage at least 3 stars $(\star \star \star)$, in classical achieve success at least $\geq 82 \% 3$ stars Develop Appropriate to Expectations.

\section{Results and Discussion}

Based on the observation results at meeting I, 2, and 3 , it can be seen that an increase happens in teacher activity, student activity, as well as the results of student's emotional social development in understanding the rules through role playing model and question-answer method in recognizing the traffic signs, it can be seen that the observation results of teacher activity is directly proportional with the observation results of student activity observation during the learning and student emotional social development result in understanding the rules using combination of role playing model and question-answer method using traffic signs medium in group B students at Insan Kamil Kindergarten.

Teacher activity of the success indicators $\geq 36$ was performed well on the learning activities because there has been increase in the activity. This is showed by the obtained score of 32 with good category at meeting $\mathrm{I}$, the score of 40 with excellent category at meeting 2 , and a score of $4 \mathrm{I}$ with excellent category at a meeting 3 which is the optimal achievement. By looking at the chart above, teachers have managed to implement the learning activities in Using Combination of roleplaying model and question-answer method through applying traffic signs medium well because it has fulfilled the achievement indicators defined.

The increasing of scores earnings of teacher activity occurs because teachers have been able to implement the phases of role playing model and question-answer method well at meeting 3, such as be able to formulate the specific learning objectives and provide explanation of the competencies to be achieved well, able to select and convey the story that will be played by students well, able to divide students into groups in fair and students are free to choose the role that will be played, guiding and directing students who have difficulty in performing the activity, as well as able to ask questions which are not too difficult but able to stimulate the student knowledge about teaching and learning that have been implemented. 
This is in accordance with Isjoni (2010) opinion that in the implementation of cooperative learning model, teachers should be more active, especially in classroom settings during the implementation, and create group tasks for the students.

The observation results about the students' readiness in learning, the student attention when the teacher delivered the material, the student's enthusiasm in role playing, as well as the student liveliness in the question-answer activity, all of them have increased. so, in accordance with what was planned in this research, the student's activity in learning using role playing model and question-answer method, recognizing traffic signs at the meeting 3 reached $95 \%$ with very active category.

It is also in line with the opinion of Catron and Allen, quoted by Sujiono (2012) that the teacher success actually emphasized on the three qualities and attitudes, that is: (I) teacher who provides facilities for student development to be well beings, (2) prepare valuable lesson by accepting students feelings and personality, and believe that basically, others are trustworthy to help create atmosphere for learning, and (3) developing empathy for the teachers to be sensitive to get to know students feelings.

Teacher of early childhood education program should have characters as follows: (I) an attitude that reflects curiosity, passion, creative, innovative, empathy, tolerance, understanding, and compassion. (2) Early childhood education program teachers should be flexible. (3) Be able to maintain good relations with all parties. (4) Having high self-confidence. (5) Having ability to engage each student in activities. (6) Tend to be a learner. (7) Early childhood education program teachers should be able to think critically in solving problems. (8) Warm but refreshing. (9) Not afraid saying something that he/she does not know. (IO) Patient to the students when they make mistake (Wibowo, 2012).

In learning process, teachers do not only play a role as model or example for the students, but also as the manager of learning. Thus, the effectiveness of learning process is largely determined by quality or ability of the teacher.
In this research, the increased activity of learning because teachers also use appropriate learning model, namely role-playing (Role Playing) and question-answer. This is in accordance with the opinion of Joyce and Weil in Rusman (2010). They argued that learning model is plan or pattern that can be used to make a curriculum (long-term lesson plan), designing learning materials, and guide learning in classroom or other places. Learning model can be used as optional pattern which teachers may choose appropriate and efficient learning model to achieve the purpose of education.

Students activity achieved success indicator by criteria of very active and has increased from the percentage value of student activity at meeting I: $26,31 \%$ with category of less active, meeting 2 : $74 \%$ with category of Active, and meetings 3: $94,73 \%$ with category of very active. Then, it can be said to be successful.

This increase occurs because the teacher motivates the students in learning activities performed, so that the students become better prepared when they are going to start learning, pay more attention when the teacher delivered the material, more active in role playing activity, and more active in question-answer activity. This is in accordance with Ramadan (2008), he states that a strong motivation is closely connected to the student's liveliness increased that is performed with strategy and learning motivation can be directed at certain activities.

The student's activity development at the Meeting of I, 2, and 3 was increased, in terms of readiness, attention, enthusiasm, and liveliness of the students. This is in accordance Santoso (2005), learning is process of change that continuously occurs within the individual that are not determined by external factors. The change occurs at views of life, behaviors, skills, perception of motivation, or a combination of these elements.

In addition, the learning is emphasizing more on the learning while playing activity which is different from the learning as usual. This is in accordance with the statement of Masitoh (2014) who said that children learn through play. Basically, playing is spontaneous activity, focused on the process, rewarding intrinsically, fun, active, and flexible. 
By role-playing performed in learning activity, then it will make the students to be more confident as the statement of Athey and Hendrick in Montolalu (2005) that playing gives children opportunity to test their bodies and see how well the limb functioning. Through playing, students feel confident physically, feel safe, and have self-confidence.

In addition, question-answer activity performed by the teacher in learning activities also have important role in developing the students' ability to express and understand what is happening in their surroundings. Speaking is a form of human behavior that controls physical, psychological, neurological, semantic, and linguistic broadly. Therefore, it may be considered as the most important tool for human in social control. Speaking or performing conversation is a favorite activity for the students. They talk while they play. The development of speaking and writing is process using expressive language in forming meaning. It often describes what they are doing during playing (Seefeldt \& Wasik, 2008).

The development results of student social emotional in understanding the rules is increased and reached category of excellent development. It can be seen from the social development results of the students emotional. At meeting I, it was only $42 \%$ of 19 students who managed to progress. At meeting 3, it was increased to $89 \%$ of 19 students who managed to progress. The teacher precision in selecting model and method is one of the key factors in developing student social emotional. In this case, the teacher combines role playing model and question-answer method in recognizing the traffic signs. The purpose of this learning is that the students can recognize various types of daily life rules. In addition, the students are also expected to be able to understand and implement the rules. In the implementation, the teachers are better in motivating, guiding, and directing the student in accordance with the syntax that has been implemented. Consequently, it can optimize the student's development.

The above explanation is in accordance with the statement of Vygotsky in Sujiono (2012) who stated that assistance can be provided to students during the activity or working on task, such as: (a) motivating or providing students interest associated with the task; (b) simplifying the tasks, so that students can easily set up and customize it; (c) providing some direction with intention of assisting to keep students focus in achieving the goal; (d) clearly showing the standards or completion from teacher about students task; (e) reducing frustration and risk; (f) giving example clearly as well as implementing expectations from displayed activity.

To optimize the student's emotional social development, teachers should be in choosing learning model precisely. Teacher as the mentor and motivator plays an important role for the students to encourage learning activities. Masitoh (20I4) stated that the learning which is oriented to development means that the approach used by teachers to implement learning is early childhood learning-oriented. It means that Kindergarten teachers should understand the needs and characteristics of the student's development by providing more opportunity to the students to be able to learn appropriately.

The development of emotional social of student development will also be successful if the learning process is fun. A fun teacher will be able to arouse the learning enthusiasm of students through the subject matter delivery in interesting ways and impressive. So that, students are happy and feel not being forced in learning.

The increasing of students learning outcome in understanding the rules through applying Role Playing and question-answer activity in recognizing traffic signs proves that the objectives of using role playing model and question-answer method is motivating, encouraging the student's interest as well as practicing a number of skills.

According to Sudjana (2004), the excellence of role-playing activity is to practice and develop student's self-confidence to be prepared facing problems. The advantage of role-playing model is to provide impression to the students, it is very attractive for the students, and it can make students understand the events that take place easily as well as can learn the lessons contained in its.

\section{Conclussion and Recomendations}

Based on the results of classroom action research that has been described, it can be concluded as follows; (I) Teacher activity in learning activity 
which is implemented by using combination of role playing model and question-answer method using traffic signs medium on group B students at Insan Kamil Kindergarten of Banjarmasin is in accordance with the syntax set and achieve the criteria of very well. (2) Students activity in learning process which is performed by using combination of role-playing model and questionanswer method through applying traffic signs medium on B group students at Insan Kamil Kindergarten can be developed and increased. (3) Students emotional social development in understanding the rules by using combination role playing model and question-answer method through applying traffic signs medium on B Group students at Insan Kamil Kindergarten of Banjarmasin has increased.

Based on the results obtained from this research, there are several things that need to be suggested for next researcher in an effort to increase the quality of human resources, as follows: (I) The headmaster of Kindergarten can provide assistance and support in form of motivation and guidance to teachers in implementing learning activities role playing and question-answer through applying traffic signs medium. (2) For teachers, role playing model and question-answer method as well as the applying of traffic signs medium is one of alternative learning models which are fun. It can be used to develop the social aspect of the students emotional, such as to introduce to the students about the various kinds of rules in everyday life. It can also make students understand more as well as implement and obey rules in the game. Furthermore, it can invite children to be actively engaged during the learning activities. (3) For the future researchers, a research by using combination of role-playing model and question-answer method can be used as reference to conduct research development on the students in getting to know and understanding the rules, one of them is traffic signs.

\section{Acknowledgment}

No acknowledgment

\section{References}

Dalle, J. (2010). Metodologi umum penyelidikan reka bentuk bertokok penilaian dalaman dan luaran: Kajian kes sistem pendaftaran siswa Indonesia. Thesis $\mathrm{PhD}$ Universiti Utara Malaysia.

Dalle, J., Hadi, S., Baharuddin., \& Hayati, N. (2017). The Development of Interactive Multimedia Learning Pyramid and Prism for Junior High School Using Macromedia Authorware. The Turkish Online Journal of Educational Technology, November. 7I4-72I.

Isjoni. (2010). Cooperative learning efektivitas pembelajaran kelompok. Bandung: Alfabeta.

Kasbolah, K., \& Sukarnyana, I.W. (2012). Penelitian tindakan kelas yang apik. Jakarta: Gramedia Widiasaran Indonesia.

Latif, M., Zukhairina., Rita, Z., \& Affandi, M. (20I4). Orientasi baru pendidikan anak usia dini. Jakarta: Prenadamedia Group.

Masitoh. (2014). Strategi pembelajaran tk. Jakarta: Universitas Terbuka.

Montolalu. (2005). Bermain dan permainan anak. Jakarta: Universitas Terbuka. 